\title{
THE GANG'S ALL HERE: GRAMMAR GOES GLOBAL FOR PURDUE, UNISA AND ADELAIDE UNIVERSITY
}

\author{
Andrea Duff \\ Division of Information Technology, \\ Engineering and the Environment \\ University of South Australia, Australia \\ andrea.duff@unisa.edu.au \\ Susanna Carter \\ Learning and Teaching Unit \\ University of South Australia, Australia \\ susanna.carter@unisa.edu.au
}

\author{
Brady Spangenberg \\ Purdue English Department/Purdue Owl \\ Purdue University, Indiana \\ United States of America \\ bspangen@purdue.edu \\ Julia Miller \\ Centre for Learning and Professional \\ Development \\ The University of Adelaide, Australia \\ julia.miller@adelaide.edu.au
}

\begin{abstract}
The University of South Australia and Purdue University (Indiana) launched the 'Grammar Gang Blog' in June 2008, as a collaborative forum for talking about language. The blog reaches a far-flung community of learners from Australia to the United States, Brisbane to Bangalore and Ghana to Germany. The Grammar Gang - where Owls meet Possums - started as a practical way to share knowledge about the function of grammar in academic writing at university. Two years later, the collaboration has grown to include the University of Adelaide. The Grammar Gang demonstrates how social software has given us an easy pathway to interact globally with those who have a common love of language. This paper discusses the way in which social software can be used for learning and global community building between students, university staff and their institutions.
\end{abstract}

\section{Keywords}

Global, language, blog, teaching, collaboration, engage, social software

\section{Introduction}

In July 2008 a friendship was forged between two far-flung partners - The University of South Australia (UniSA) and Purdue University in Indiana. This partnership saw the launch of The Grammar Gang blog - a collaborative forum using social software to explore the use of Grammar in a university setting. In 2010, the University of Adelaide became the third institutional partner.

The Grammar Gang blog is a meeting place where Purdue 'owls' meet UniSA/University of Adelaide 'possums' to write pithy and timely blog posts about all things language-related, but with a particular focus on grammar. The blog was established as a way in which each organisation could 'add value' to the delivery of its student academic language services. Purdue saw an opportunity to use UniSA's burgeoning experience with blogs and social technology, while UniSA saw a transcontinental collaboration with Purdue and its famous Online Writing Lab (OWL) resources as a coup for each respective organisation. The University of Adelaide came on board because we wanted to expand our collaboration and include another team member keen on grammar. 
All three institutions possess a track record in developing and proliferating electronic learning and teaching tools, but practical work with social software was nascent at the time of the creation of the Grammar Gang.

The Grammar Gang provides a platform for collegiality and an ability to engage in the scholarship of teaching in learning in the most practical sense (Prosser, 2008). We hope the reflections in this paper provide food-for-thought about the way in which other learning, teaching or discipline-based units can use the tools freely 'out there' to create rich, collegial experiences. The Grammar Gang has become a global collaboration between three like-minded spirits who care very much about how communication in the academic context is advanced by language competence.

This paper will discuss some of the organizational aspects related to working across borders and tertiary institutions, while demonstrating how the blog reaches out to a global audience. It will also discuss some observations around the use of English.

\section{From bricks and mortar to a borderless environment}

Notwithstanding the provision of fairly static online learning resources, the services provided by the three institutions are largely contained within brick-and-mortar walls. This, in turn, generates three main concerns. First, the individualized consultation process makes it difficult to sustain a continuation of discussions between tutors/advisers and clients. Second, few lasting artifacts of these conversations are produced, meaning that the results of previous sessions do not generally figure into future sessions. Thirdly, existing Web 1.0 online resources tend not to have the interactivity to make them fully engaging. It is widely known that an effective learning environment requires collaboration, engagement and a sense of community (Duff, \& Quinn, 2006; Oliver, Herrington, Herrington, \& Reeves, 2007).

As a centrally-located, editable blog, the Grammar Gang seeks to address each of these concerns. It archives all previous posts and discussions and, through search engine technology, each of these individual discussions is readily accessible - keeping the discussion evolving. For the blog's readers and contributors, these features provide a stronger, more stable foundation upon which to build language competence. The community is evident via polls; comments; voting on posts; the community of bloggers and ClustrMaps (which provides visual 'evidence' that people are coming in from all over the world). This level of interactivity and engagement is not present in static Web 1.0 resources.

Facebook, MySpace, Twitter and Blogger are daily staples for students and a growing number of their lecturers and institutions. Social software has become an increasing, systemic and expected part of the everyday business practice of large organisations - evidenced by the websites of large media organisations such as the ABC (Johnston, Duff, \& Quinn, 2009, p. 29). Oblinger and Oblinger (2005) suggest social technologies are so woven into the ways in which students communicate that they do not even think they are using "technology" (p. 21).

\section{Managing the collaboration}

The Grammar Gang is managed through monthly editorial meetings using the synchronous videoconferencing tool, Skype. Topics are often negotiated, but spontaneity is encouraged and often the Grammar Gang's four editors will post topical issues as they come up. Decisions are made regarding the types of posts and ideas to generate interactivity. For example, an early post The Grammar Olympics (Figure 1) encouraged readers to use language in creative ways. In its early days (which coincided with the 2008 Beijing Olympics) the team set linguistic challenges to give students an opportunity to practise their skills, such as writing the longest sentence, and writing the longest sentence which uses the most silent letters. A prize was sent to the winning entry - a follower from Bangalore. 

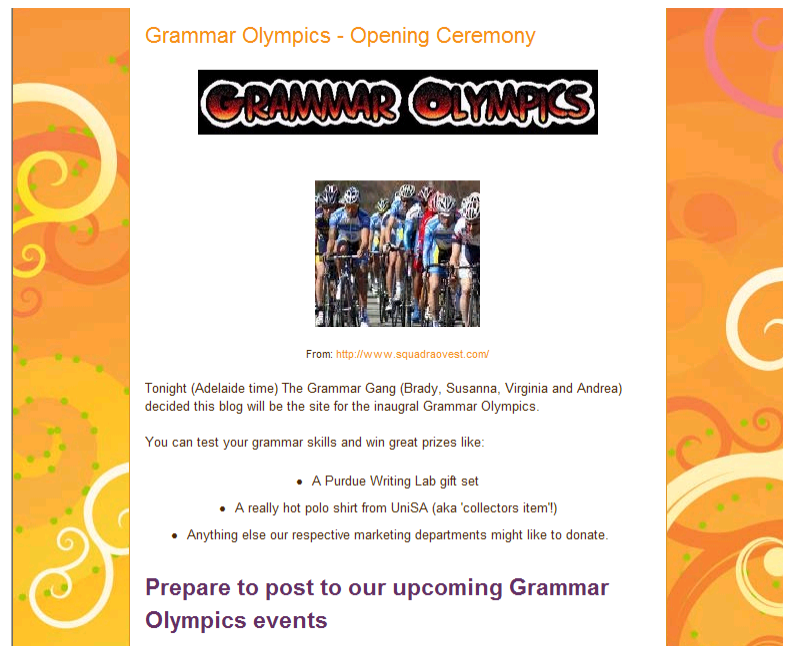

Figure 1: The Grammar Olympics (August 12, 2008).

Early on, there were some minor frustrations, such as learning the technologies of Blogger and Skype. Synchronising meetings was also a challenge because of the time difference between each country. This was helped by the insertion of a 'World Clocks' widget in the side navigation bar of the Grammar Gang.

\section{Toward a shared pedagogy}

The biggest area to manage was a difference in pedagogies. The Purdue contributions favoured the sentence and the UniSA contributions favoured the 'bigger picture' issues of culture, genre and systemics. It can be noted, in passing, that the University of Adelaide favours the same approach.

It also became a challenge to adapt the respective pedagogies to an online learning environment. Purdue, based on the OWL model, favoured a more information-based approach, while the UniSA contributions invited more interaction from the blog's users. As the blog has evolved, posts tend to combine interactivity - content and user engagement - in a much more integrated way. For example, Figure 2 shows how the debate between new and old languages comes to a head, when readers are asked to vote on "Professor Codswallop's" assertion that "SMS language will see the end of language as we know it". Eighty-eight participants voted on the poll with $61 \%$ acknowledging that SMS is having some impact on language and a further $26 \%$ agreeing "Professor Codswallop is ignoring our ability to move from one context to another". The post gave a lecturer an opportunity to talk about the inappropriateness of using SMS language in emails.

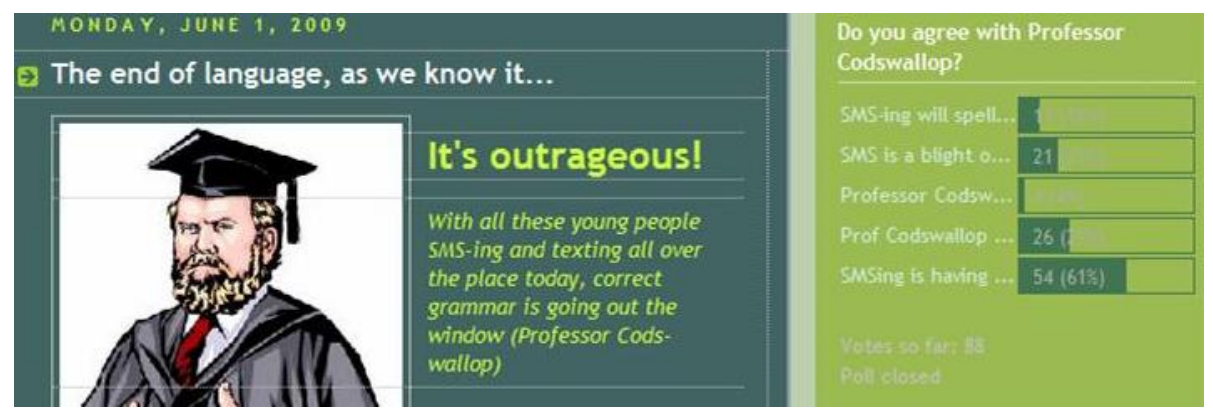

Figure 2: The end of language as we know it (June 1, 2009)

Scollon and Scollon (1995) pointed to the multifarious ways in which grammar and language are taught. Compounding this is the fact that people all over the world talk - even in English - in 
many different ways so it is very difficult to come up with a definitive 'style guide' in teaching English (Crystal, 2001a). This is one of the blog's strengths, as having contributors in different countries adds to the wider dimension of cross-cultural information exchange.

The PurdueWriting Lab operates largely under the pedagogical umbrella outlined by Williams (1990) in the "Little Red Schoolhouse" at the University of Chicago. This philosophy involves graduate students and advanced undergraduates to work with less senior students as expert writers with specialist knowledge of their field (University of Chicago, n.d.). Williams (1990) advocated "a grammar of style that ... characterizes 'reader-friendly' prose in all fields" (p. 89). In other words, Williams downplayed traditional notions of syntactic grammar that judges rightness and wrongness, according to universal a priori grammatical structures.

That said, many of Purdue's famous OWL resources focus quite specifically on grammar and mechanics and certainly contributions made by Purdue to the Grammar Gang tended to focus on sentence level grammar analysis, as indicated by this post on the principal parts of a verb (see Figure 2).



Figure 3: The principal parts of a verb (November 7, 2008).

While the possums (from both UniSA and Adelaide University) are flexible in their approach ('what works'), they tend to favour Halliday's systemic functional linguistics (Halliday, 1994) and genre analysis (Swales, 1990). Syntax and grammar are looked at as a means to achieve this.

The teaching of genre makes explicit culturally-bound practices which are embedded in the discursive practices of members of specific disciplinary cultures such as engineering, health sciences or education (Bhatia, 1993). There is a strong emphasis at UniSA and Adelaide University on embedding language and learning support within a disciplinary context (Candlin \& Mercer, 2001; Skillen, Merten, Trivett, \& Percy, 1998). A series by UniSA in November 2009, 'The anatomy of an essay' looked at the meta-generic elements of essay writing suggested by Kaldor, Herriman and Rochecouste (1998) which pointed to the importance of form, sections, academic skills such as referencing and sentence level editing (as the last step in the process). 


\section{The Grammar Gang brings us together}

Notwithstanding the different pedagogies, the collaboration has made for an exciting and universal approach to the problem of dealing with language, structure and use. Both the Owl and the Possums accept and embrace the differences as offering a holistic approach to students. The fluidity of the media enables authors to flip seamlessly between sentence and context, grammar rules and cultural norms. The participants decide on the post theme (verbs, nouns, academic language and culture) and comments are posted by readers to voice concerns, make observations or suggest solutions to quandaries. The blog provides deep and engaging learning strategies which move students from transmissive 'sage on the stage' models of education to a colourful and interactive model which sustains interest, provides meaning and gives relevance to the wider world (Biggs, cited in Duff, Quinn, Johnston, \& Lock, 2008).

\section{Community and reach}

Google Analytics and ClustrMaps provide numerical evidence of growth and community.

From Google Analytics we can see, for example, in the month between June 29 and July 29, 2009 there were 3,141 visits to the site. During this time, the five most popular posts were:

- Does it even matter? (A post debating whether it is even important to have good grammar in academic writing by the $\mathrm{Owl}$ )

- Nicer than the nicest (a post about the correct expression of comparatives by the Owl)

- Grammar tips for academic writing (UniSA)

- Writing like a Native: More quick tips for ESL writers (Owl)

- The end of language as we know it (a post about the use of SMS language questioning its impact on writing by UniSA

Google Analytics also show us that visitors came from countries as disparate as Lithuania and Rwanda (one visitor each) to the United States (which provided 1,786 visitors), Canada (219), Australia (175) and India (119). Some of these visitors spent, on average, as little as one second on the site (Belgium) to as long as eleven minutes and 15 seconds (Denmark).

Data gathered on ClustrMaps shows 27,672 visitors between July 31, 2008 and July 31, 2009, when the tool was first installed. Between August 2, 2009 to August 3, 2010 this number had almost doubled to 53,879 visits as the blog incorporated more interactivity between other social media such as Facebook.

These impersonal figures certainly indicate that blog use is growing. While figures over the past twelve months are vast in number, they are arguably less powerful than the 155 or so 'blog followers' (See Figure 4) who chip into the conversation, link the blog to their favourite sites and add a global face to the Grammar Gang. In becoming members of the Grammar Gang, they link off to other blogs they have chosen to become members - creating even more opportunities for global distribution.

Some of these followers include 'Nagi' a law student who has 'writing scattered across the Internet'; Poet 'Daniel', a student of Durham Technical Community College, originally from Ghana and Bobchiin, 'a stranger in a strange land' who has taught in Japan. 


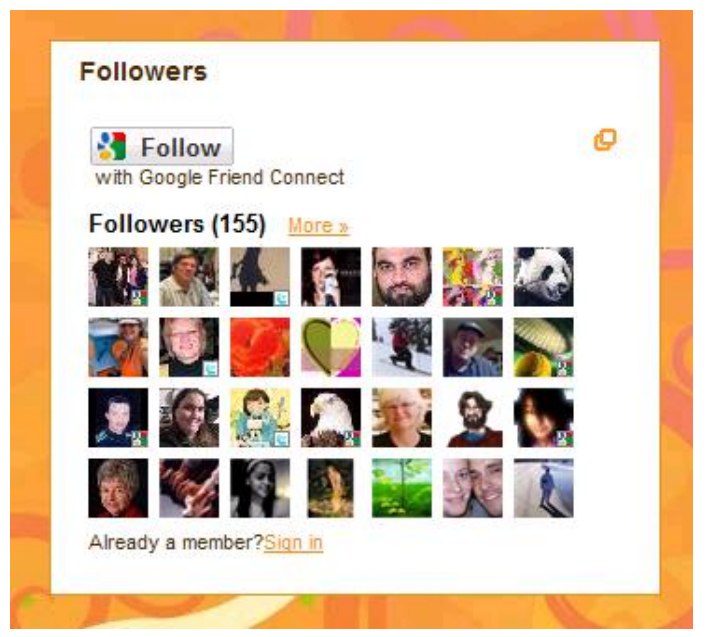

Figure 4: Blog Followers (August 5, 2010)

Finally, the posts themselves have inspired those from the global community to provide their own rich input, and in a few cases, deeply held sentiments. The following examples provide a snapshot of the 110 comments contributed to the Grammar Gang's twenty nine posts.

- $\quad$ Staff from Purdue ask the question whether 'whom' still exists (January 16, 2009), and from the debate that ensued, one can affirm that 'whom' certainly does.

- A 16-year-old OJ from New York (June 10, 2009) refutes the claim that SMS texting will see the end of language as we know it.

- PurrPrints from 'Somewhere' joins the lament about the variable nomenclature surrounding coffee cups sizes (June 29, 2010)

- Dedene from France (April 7, 2009) shares with us different colloquial ways of describing weather (il pleut des cordes - 'it's raining buckets')

- Kathy, a 'self-confessed member of the grammar police' (December 7, 2008) owns up to her Achilles heel - the differences in spelling between 'practice' and 'practise'.

- Roddy, an EAL student (September 2, 2008), sends a 'red pen' sentence to fix.

\section{What the Grammar Gang has taught us}

The Grammar Gang has provided some surprising and powerful insights into the blog's propensity to bring together community and provide insights into language. In many ways, it has exceeded our expectations in terms of its uptake and engagement. For example, we did not expect to be cited in a review of grammar blogs and also we did not anticipate the level of enthusiasm for grammar world-wide. There is certainly a place on the web for an open discourse about grammar and language usage which targets an audience at tertiary level.

\section{Global Englishes}

In addition to indications of use, growth and community, examining the Grammar Gang also gives insights into the ways in which the Internet has broadened acceptance of a variety of Englishes. In support of this, Pennycook (2001) has pointed to a continuing debate among EAL teachers regarding the standardisation of English versus the acceptance of other English varieties. The Grammar Gang demonstrates that at least three varieties of English can co-exist - US English, Australian English and "Netspeak" (Crystal 2001b, 2006). It is clear that there are 'a great many ways' to speak or write a language such as English and many of us are able to use different language or social styles depending on the setting (Gee (1999). Indeed, in such an unconstrained and open environment such as the Internet, they must. 
This necessary difference does not detract from the effectiveness of the blog. As electronic communication pushes the old orders of English further into the background there exist fewer and fewer standards of judgment by which English speakers and writers can judge correctness. This is seen in the case of the post "Does 'Whom' still exist"? (January 16, 2009) which tackled a grammatical question and the cultural relevance of the 'Queen's English' in academic writing.

Diehl and Prins (2002) challenged the assumption of the superiority of one English over another in the online environment. Crystal (2001a) highlighted how neat 'garden variety' English has been decimated by a rapidly burgeoning collection of Englishes and that, while it is important to maintain an international standard, there is a strong need to "recognise international diversity, as a reflection of identity, chiefly in speech and eventually in writing" (p. 63). This is manifest in the Grammar Gang where 'full-stops' are referred to as 'periods' and words like 'organisation' and 'realise' are spelt with a 'z' instead of an 's'.

Finally, the great irony of the Grammar Gang is that the formalities of English are often debated with smatterings of informal 'Netspeak,' with its incomplete sentences and expedient spellings. Crystal (2001b, 2006) explained the defining feature of language on the Internet as being where the writing appears to be spoken. This "raises the question of linguistic identities in fresh and intriguing ways" (Crystal, 2001b, p. 55). One of the effects, according to Crystal, is 'hybridization' of the language which, on the Internet; is manifest in the array of punctuation, spelling, and syntactical styles noted in the posts and comments on the blog.

\section{Discussion and Conclusion}

The Grammar Gang demonstrates how using Web 2.0 technologies can empower the practice of those working in academic language and learning in a most practical sense. Blogs are an intrinsically and well known part of the social technological landscape which transcend geographical boundaries.

The data presented around growth and outreach, along with the ways in which language is explored, poses some interesting possibilities for academic language and learning services. Firstly, a collaboration of this nature would have been unimaginable ten years ago. Even the writing of this paper has been made possible through the use of social technologies such as Google Docs and Skype. Such freely available online technologies have the potential to simplify, disseminate and collaborate in our daily practice.

Secondly, the Grammar Gang has enabled the creation of new ways of operating. Its growing popularity demonstrates that cross-institutional collaboration is a rich and scholarly thing to do. Although there are some marked differences in pedagogy, it has created a space where each practitioner can take the best aspects of their practice (whether with sentence or genre), combining the best of two worlds.

Thirdly, multiple points of distribution of the Grammar Gang through Facebook and other social networking tools have disseminated not only the blog, but the writing and academic skill-building resources of the institutions.

Further, the blog has made us more aware of, and conversant with, the linguistic and cross cultural boundaries of three cultural entities - the US, Australia and the Internet. The Grammar Gang has provided a space for a global melting pot of multiple perspectives in language and allowed for a meeting of minds in ways that were not imaginable prior to the development of Web 2.0 technologies.

Most importantly, perhaps, integrating the blog into practise is a recognition that social technologies are essential to and increasingly expected by our net-savvy students. Skene and 
Cluett (2008) pointed to the importance of using social networking to engage the 17-30 year old commencing undergraduate population who spends increasingly less time on campus.

Through the Grammar Gang, the Purdue, UniSA and Adelaide University team have confronted, shared and eventually celebrated differences in style and pedagogy. The overarching goal of the team is to provide academic support to our students who increasingly expect a modern and engaging environment (Oblinger \& Oblinger, 2005). These globe-trotting endeavours provide a joyous, welcome (but no less valuable) repose from the more traditional elements of our day-today work.

\section{Acknowlegements}

Associate Professor Linda Bergmann, Director of the Purdue Writing Lab; Helen Johnston; Virginia Hussin, Grammar Gang contributor.

\section{References}

Bhatia, V.K. (1993) Analysing genre. Harlow, UK: Longman.

Candlin, C., \& Mercer, N. (Eds.). (2001). English language teaching in its social context. London: Routledge.

Chomsky, N. (1969). Aspects of the theory of syntax. Cambridge, MA.: MIT:

Crystal, D. (2001a). The future of Englishes. In A. Burns, \& G. Coffin, (Eds.), Analysing English in a global context: A reader (pp. 53-64). London: Routledge.

Crystal, D. (2001b). Language and the Internet . Cambridge: Cambridge University Press.

Crystal, D. (2006). Language and the Internet. ( $2^{\text {nd }}$ ed.). Cambridge: Cambridge University Press.

Diehl, W. C., \& Prins, E. (2008). Unintended outcomes in Second Life: Intercultural literacy and cultural identity in a virtual world. Language and intercultural communication, 8(2), 101-118.

Duff, A., \& Quinn, D. (2006). Retention in online courses: Using a motivational framework to enlighten potential learners about learning online. Journal of Learning Design, 1(3), 29 - 39.

Duff, A., Quinn, D., Johnston, H. \& Lock P. (2008). A clue, a quest and a blog - Experimenting with engagement in orientation. Proceedings of the First Year in Higher Education Conference (pp. 1- 10), July 5 - 6. Brisbane.

Gee, J. P. (1999). An introduction to discourse analysis: Theory and method. London: Routledge.

Halliday, M.A.K. (1994). Introduction to functional grammar ( $2^{\text {nd }}$ ed.). London: Edward Arnold.

Johnston, H., Duff, A., \& Quinn, D. (2009). Cutting the cloth to fit new needs and communication preferences. The Journal of the Education Research Group of Adelaide, 1(2), 27 - 38. Retrieved July 30, 2009, from http://www.adelaide.edu.au/erga/ergo/ergo_v1n2_p27-38.pdf

Kaldor, S., Herriman, M., \& Rochecouste, J. (1998). Tertiary student writing: Framing student literacy - Cross - cultural aspects of communication skills in Australian university settings. NCELTRE Macquarie University in association with the University of Western Australia, Sydney.

Oblinger, D., \& Oblinger, J. (2005.) Educating the net generation. Retrieved July 31, 2009, from http://www.educause.edu/educatingthenetgen

Oliver, R., Herrington, A., Herrington, J., \& Reeves, T C. (2007). Representing authentic learning designs supporting the development of online communities and learners. Journal of Learning Design, 2(2), 1-21.

Pennycook, A. (2001). English in the world/the world in English. In A. Burns, \& G. Coffin (Eds.), Analysing English in a global context (pp. 80 - 87). London: Routledge.

Prosser, M. (2008). The scholarship of teaching and learning: What is it? A personal view. International Journal for the Scholarship of Teaching and Learning, 2 (2), 1-4. 
Scollon, R., \& Scollon, S. (1995). Intercultural communication: A discourse approach. Oxford: Blackwell.

Skene, J., \& Cluett, L. (2008). 'If you build it, they will come': The challenges of developing a social networking site in a university context. Proceedings of the First Year in Higher Education Conference, Hobart, Australia, June 30 - July 2.

Skillen, J., Merten, M., Trivett, N., \& Percy, A. (1998). The IDEALL approach to learning development: a model for fostering improved literacy and learning outcomes for students. Proceedings of the Australian Association for Research in Education Conference, Adelaide. Retrieved July 30, 2009, from http://www.aare.edu.au/98pap/ski98343.htm

Swales, J.M. (1990). Genre analysis: English in academic and research settings. Cambridge: Cambridge University Press.

University of Chicago (n.d.) University of Chicago writing program. Retrieved August 2, 2009, from http://writing-program.uchicago.edu

Williams, J. (1990). Style: Toward clarity and grace. Chicago, ILL: University of Chicago Press.

Copyright @ 2010 Andrea Duff, Susanna Carter, Brady Spangenberg, Julia Miller 